\title{
An Advocacy for Marine Protected Areas Initiative for Conservation of Ecological Resources and Survival of Coastal Communities in Nigeria
}

\author{
Fie David Dan-Woniowei \\ Department of Political Science, Niger Delta University, Wilberforce Island, Nigeria
}

\section{Email address:}

fieddanwoniowei@gmail.com

\section{To cite this article:}

Fie David Dan-Woniowei. An Advocacy for Marine Protected Areas Initiative for Conservation of Ecological Resources and Survival of Coastal Communities in Nigeria. Journal of Political Science and International Relations. Vol. 3, No. 3, 2020, pp. 56-60.

doi: $10.11648 /$ j.jpsir.20200303.12

Received: July 31, 2020; Accepted: August 18, 2020; Published: August 27, 2020

\begin{abstract}
The marine protected areas (MPAs) initiative is a globally recognized area-based environmental safety and resources conservation tool. It is mostly utilized for preserving marine biodiversity loss and ecosystem services. The instrument has been proven since introduction for mitigating against biodiversity loss by promoting the persistence, recovery and growth of marine populations around aquatic regions of the world. The Niger Delta has been a misery of adverse ecological and economic disorders for over sixty decades of ceaseless exploitation of oil and gas resources. Available records show that the Nigerian government is not oblivious to the environmental woes affecting various parts of the country, and also have not derailed to tackling them through various environmental safety and conservation initiatives. However, the vital MPAs' initiative have not been considered by the Nigerian government in its efforts to tackling the environmental crisis related to the oil-rich Niger Delta. This advocacy is thus envisaged as a wake-up call for the Nigerian government and other international conservation agencies to look towards the coastal areas of the Niger Delta in order to realize the long-term goal of conserving the ecological resources and ensure the survival of the indigenous people of the region. Secondary data relating to marine protected areas across the globe used in the analyses.
\end{abstract}

Keywords: Advocacy, Marine Protected Areas (MPAs), Ecological Resources, Survival, Coastal Communities, Nigeria

\section{Introduction}

Progress towards bringing about environmental safety and conservation of ecological resources in most aquatic regions of the world has relied on a number of initiatives. Suffice to state that Nigeria like many other countries was not oblivious to such global efforts and have long established laws and formal governmental structures towards tackling rising cases of environmental concerns in the country [1], but not much has been achieved pertaining to the Niger Delta. In particular, mapping out parts of the coastal regions as marine protected areas (MPAs) as a means for conserving the biodiversity and ecosystem services vital for the survival of the coastal communities is currently lacking in the country. The MPAs' initiative is one of the globally recognized area-based conservation mechanism for safeguarding marine biodiversity loss and ecosystem services decay in most aquatic regions of the world [2, 3]. This vital tool has proven to promoting environmental safety and resources conservation by mitigating marine biodiversity loss especially in oil and gas producing aquatic regions of the world.

Different studies have shown the relevance of the MPAs and successes currently recorded in some marine regions of the world in mitigating biodiversity loss by promoting the persistence, recovery and growth of marine populations [2]. Available records show that there are approximately 13,000 MPAs in various parts of the world, some covering areas as large as $100,000 \mathrm{~km}^{2}$ [3-5]. The MPAs of this magnitude are known as large-scale marine protected areas (LSMPAs) [6]. Available records show that from 2004 and beyond 2010, the MPAs' coverage was more than $80 \%$, which was more than 11 million $\mathrm{km}^{2}$ and represented by ten LSMAs around the world [3, 5]. Majority of these LSMPAs are located within the Exclusive Economic Zone (EEZ) of coastal states such as the United Kingdom [7]. 
Surprisingly, there is currently, no single MPA within the Atlantic shores of Nigeria's Niger Delta, or has there been any existing plan to establish one in the area to safeguard the ceaseless biodiversity loss, natural resources decay and survival of the indigenous people in the region. Such disposition of the Federal Government of Nigeria in a region where massive exploitation of oil and gas resources hugely impact the daily life of the people for the past fifty decades is a misnomer and calls for urgent concern. It is even more worrisome for the fact that human well-being and ecosystems are inextricably linked [8]. Humans survive through the goods provided by ecosystems such as forest products (food as marketable goods), and non-marketable ones as services including water flow regulation, storm protection, amongst others pertinent for the survival of the coastal communities in the region. The marine resources provide the income, food, and recreation as well as other benefits for the indigenous people of the region.

More worrisome is the fact that biodiversity destruction and human welfare loss are the daily living conditions for the indigenous people of the coastal communities in Nigeria's Niger Delta. This advocacy is therefore, necessary for all stake holders of the oil and gas business in Nigeria to ensure that certain heritage sites (the mangrove forest zones) and ecological resources are conserved through the establishment of at least an MPA with connectivity in the region to prevent the ceaseless destruction of the livelihoods of the people. It is envisaged that the adoption of the MPA will engender some form of help by providing the most needed long-term conservation of the ecological resources already threatening extinction in the region.

\section{MPAs as Global Conservation Instrument}

Over the years, a number of global agencies such as the International Union for the Conservation of Nature (IUCN) and the Convention on Biological Diversity (CBD) have initiated moves to ensuring that long-term conservation of nature with associated ecosystem services and cultural values are preserved [9]. While providing the working plan, the IUCN define MPAs as a clearly designated geographical space, recognized, dedicated and managed, through legal or other effective means, to achieve long-term conservation of nature with associated ecosystem services and cultural values [10]. The CBD on it part, define MPAs as a geographically defined area (s) which are designated or regulated and managed to achieve specific conservation objectives [11]. Looking at the two definitions in the same lens with [9], the IUCN and CBD confer on the subject the same meaning and significance. Not only that, the agencies involvement accords the MPAs' initiative a global recognition and significance.

Furthermore, the CBD commitments or Programme of Work which expressly reinforces the IUCN protected areas initiatives [9], resulted to setting a new Strategic Plan for 2011-2020. The Strategic Plan envisaged to undertake effective and urgent action to halt loss of biodiversity and ensure that by 2020 ecosystems are resilient and continue to providing essential services, thereby securing the planet's variety of life, and contributing to human well-being, and poverty eradication [12]. In affirmation, the CBD provides the most comprehensive legal framework for protected areas in setting the target to conserve at least 17 per cent of the terrestrial and inland water areas by the year 2020, especially areas of particular importance for biodiversity and ecosystem services are conserved, through an effective and equitable management plan, ecologically representative and well-connected systems of protected areas and other effective area-based conservation measures, and integrated into the wider landscapes and seascapes [11]. To realize this objective, the CBD collaborated its efforts through a number of international legal instruments and facilitated the process. The instruments includes: the 1982 United Nations Convention on the Law of the Sea (UNCLOS); the 1992 Convention on Biological Diversity (CBD); the 1971 Convention on Wetlands of International Importance Especially as Waterfowl Habitat (Ramsar Convention); the 1979 Convention on Migratory Species of Wild Animals (CMS); the 1973 Convention on International Trade in Endangered Species of Wild Fauna and Flora (CITES); the 1946 International Convention for the Regulation of Whaling (ICRW); the 1972 Convention Concerning the Protection of the World Cultural and Natural Heritage (WHC); and the 1973/78 International Convention for the Prevention of Pollution from Ships (MARPOL) [11, 13]. Another international legal instrument which played an additional role in the creation and management of MPAs include the 1992 United Nations Framework Convention on Climate Change $[11,14]$. Some countries that have domesticated these protocols are making frantic efforts to ensure that nature is preserved for future generations.

The MPAs are of different categories. Six of the protected areas management categories identified by [9], which were recognized also by the IUCN and CBD includes (Ia) strict nature reserves and (Ib) wilderness areas; (II) national parks; (III) natural monuments or features; (IV) habitat/species management areas; (V) protected landscapes or seascapes; and (VI) protected areas with sustainable use of natural resources. It has been suggested that the applicable category should be based on primary management goal (s) of the protected area. In addition, the primary management goals should apply to at least three-quarter of the protected area, the so-called "75 per cent rule".

The point must also be made that MPAs design may vary broadly from whole to "no-take" marine areas where fishing and other extractive activities are forbidden to "multiuse". The MPAs' initiative should also guarantee allowance for certain levels of commercial fishing, extraction and other human uses in particular areas [15]. It is also important for MPAs to have direct, inferential or predictive measures of ecological connectivity among protected areas [2]. The extent to which an MPA is having spatially distinct populations, communities, ecosystems, or habitats and linked by the 
exchange of genes, organisms (propagules, juveniles and adults), nutrients, and energy is referred to as ecological connectivity [2]. Ecological connectivity governs the exchange of individuals among spatially fragmented habitats and is often highlighted as an important element in the design of MPAs [2]. Five categories of networks of MPAs (MPAn), which ranges from ad-hoc (an unplanned collection) to connectivity-based (multiple ecologically connected MPAs) were identified by $[2,16]$, which they also argued, many of the existing MPAn (s) do not meet the definition of a connectivity network.

Availability or connectivity notwithstanding, the Nigeria's Niger Delta is bereft of all the listed categories. Urgent steps should therefore, be taken to establish MPAs in the region to ensure long-term conservation of the fast eroding cultural values of the indigenous people of the region.

\section{Relevance of the MPAs' Initiative in Nigeria's Niger Delta}

Several concerns have been growing around the globe about the declining nature of marine biodiversity particularly in oil and gas producing aquatic regions with the commitments to designate MPAs to tackling the menace. Some of such commitments include the Programme of Work on Protected Areas, the Global Strategy for Plant Conservation, the Strategic Plan on Biodiversity and the Programme of Work on Marine and Coastal Biodiversity [13]. Obviously, such global strategic efforts concerning the Niger Delta area is absent. This is a region where exploitation of oil and gas resources by Multinational Oil Corporations (MNOCs) have been ongoing for the past fifty decades. Various studies have also shown that their operations severely impact on the major habitats - the Atlantic Ocean, seas and estuaries, creeks and mangrove forests among others in the region [17]. The impact on the ecosystems is so huge that it affects the traditional economy and welfare of the coastal communities. Therefore, the protection and sustainable use of the environmental resources should become a subject of intense regulations [18]. This is very crucial as coastal communities rely on the marine ecosystems for survival. For example, the mangrove habitat provides a wide range of goods and services beneficial to man [19]. Such ecosystems goods and services provided by the mangrove forest include habitats for many aquatic organisms and animals, and fuel for the coastal communities, as well as protective barriers for the communities against storms and tidal waves/coastal erosion. In addition, the list of the services was increased to cover shoreline protection, stabilization, filtration, trapping and removal of water-borne pollutants, maintenance, nursery and feeding grounds for numerous species of finfish and prawns, habitat for crabs and molluscs, as well as nesting sites for sea and shore birds [20]. Consequently, an alteration on the ecosystems through reckless petroleum production activities could spell doom for the communities in the region. For example, the depleting mangrove regions of the Niger Delta poses serious concerns [20]. The imprints of the MNOCs on this is obvious throughout the Niger Delta. The imprints caused by oil spills are "homicidal in effect [21]". Studies have shown that mangroves are susceptible to oil. That when oil spill occurs, the soil retains part of the oil and re-leases it annually during inundations, and gradually destroys an estimated 5 to $10 \%$ tracts of mangrove forests in the region. Evidently, Nigeria's mangrove forests are fast depleting annually as a result of oil exploration and production activities, and uncontrolled use by locals. Some oil industry activities that have led to mangrove vegetation disappearance include cutting of seismic lines, laying of pipelines and construction of flow stations. The clearing of the mangrove vegetation for these activities causes many problems. For example, studies have shown that mangroves take between 30 to 40 years to regenerate once they are removed.

In addition, pollution from oil spills impact adversely on the fisheries resources of the Niger Delta [22]. Pollution matters are highly controversial in Nigeria. As a result, it is very difficult to have a correct oil spills data from the industry regarding offshore platforms and vessels collocating coastal regions of the country. However, indirect evidence from oil washed secretly into the shores of the coastline and/or from open accidents recorded in the past in the area by ongoing development activities of offshore platforms suggest that the once pristine coastal mangrove forested region and beaches have become increasingly vulnerable. Oil spills affect the mangrove habitats when it permeates exposed tree trunks and accelerates the rate of its decay and later destroys the precious plants. Consequently, it leads to their disappearance, and communities are exposed to shoreline erosion. Pollution also causes devastation of flora and fauna, migration and extinction of creatures big and small that depend on mangroves as their habitat.

More than that, oil spillages badly affect the livelihoods of communities and individuals, especially coastal communities and fisher folks [17]. This is because the traditional economy of the Niger Delta people depends mostly on environmental resources. Due to oil and gas development and production activities around coastal communities, the people experiences low income yearly in their traditional fishing industry, there is food insecurity and poverty in the region. Truly, the economic conditions in the Niger Delta unequivocally depict endemic poverty [23], which is worse by the day due to oil pollution such that the habitat has limited the productive capacity of the people. Obviously, fisher folks in recent years have suffered massive reduction in fish catches due to oil spills. The offshore operations of MNOCs affect fish populations, especially at vulnerable spawning seasons, because of the presence of physical structures and a range of techniques used. The most serious impact on fish population is the disruption of natural spawning processes of both anadromous and catadromous fish species. The presence of oil makes it unsafe for spawning processes. This affects the ability of the wild to replenish itself. The results ultimately include low fish population and catch, and hence lower or inadequate fish supplies and income as well as attendant malnutrition in the region. 
It is therefore, very important to protect the menace of biodiversity loss by establishing the MPAs' conservation mechanism in the Niger Delta. This will safeguard the ongoing abysmal loss of the region's environmental resources and the fast decaying cultures of the people.

\section{Conclusion}

MPAs are geographically defined territories, essentially created and regulated as tool for conserving the almost extinct ecological features and marine populations of the world for the sustenance of human existence. It was identified that such vital instrument was non-existent in the Atlantic shores of Nigeria as means to addressing the ceaseless environmental damage occasioned by oil and gas exploitation in the Niger Delta. The advocacy was able to point out also that the MPAs' conservation tool is relevant in the region. As a result, it was suggested that the Nigerian government should collaborate with international organizations such as the IUCN, CBD and NGOs among others to ensure that MPAs with connectivity are established and managed in the Nigeria's Niger Delta to safeguard the fast decaying cultures and value systems of the indigenous people and their future generations.

Some suggested possible actions:

It is advocated that there should be intensive collaboration between and among key actors both at the international and local levels such as the IUCN, CBD and other conservation organizations, the Federal and State Governments of Nigeria, and Non-Governmental Organizations (NGOs) on issues relating to the establishment and management of marine protected areas in the Niger Delta.

Other specific actions could include:

1) Establish a multi-stakeholder forum to build consensus to achieve on 'no-go' zones for oil and gas activities, on a case-by-case basis, with a priority for World Heritage Sites;

2) Develop a package of published 'better-practice' guidance on oil and gas operations around would be protected areas;

3) Establish clear criteria that can be used to decide if oil and gas operations are possible near would be protected areas, which should then be applied to as control and assessment of existing exploiting areas;

4) Work towards improving transparency of decision-making around the possible areas that need protection and the category and linkages; and

5) Undertake 'high resolution' mapping of possible sites through key institutions that will identify the scale and extent of threats and opportunities for the would be protected areas that oil and gas operations and other sectoral activities may pose.

\section{References}

[1] National Policy on the Environment (Revised 2016). Federal M.
[2] Balbar, A. C. \& Metaxas, A. (2019). The current application of ecological connectivity in the design of marine protected areas. Journal of Global Ecology Conservation, 17, 1-20.

[3] Read, A. D., McBride, C., Spencer, T., Anderson, P., Smith, J., Costa, T., Clementz, S. \& Dowd, A. (2019). Preventing noncompliance in marine protected areas using real-time alert system. Ocean and Coastal Management, 173: 123-130.

[4] O'Leary, B. C., Ban, N. C., Fernandez, M., Friedlander, A. M., García-Borboroglu, P., Golbuu, Y., Guidetti, P., Harris, J. M., Hawkins, J. P., Langlois, T., McCauley, D. J., Pikitch, E. K., Richmond, R. H., Roberts, C. M., 2018. Addressing criticisms of large-scale marine protected areas. Bioscience 68: 359-370.

[5] Lewis, N., Day, J. C., Wilhelm, T.'A., Wagner, D., Gaymer, C., Parks, J., Friedlander, A., White, S., Sheppard, C., Spalding, M., San Martin, G., Skeat, A., Taei, S., Teroroko, T., Evans, J. (2017). Large-scale Marine Protected Areas: Guidelines for Design and Management. IUCN, Gland, en. https://doi.org/10.2305/IUCN.CH.2017.PAG.26.

[6] Friedlander, A. M., Wagner, D., Gaymer, C. F., Wilhelm, T. a., Lewis, N. a., Brooke, S., Kikiloi, K., Varmer, O., (2016). Co-operation between large-scale MPAs: successful experiences from the Pacific Ocean: cooperation between Pacific Large-Scale MPAs. Aquat. Conserv. Mar. Freshw. Ecosyst. 26: 126-141.

[7] De Santo, E. M. (2019). Militarized marine protected areas in overseas territories: Conserving biodiversity, geographical positioning, and securing resources in the $21^{\text {st }}$ Century. Ocean and Coastal Management, 1-13.

[8] Chittirapap, C. (2016). Chapter 3: Human vulnerability to environmental change. UNEP, Thopam Picturepoint, 302-317.

[9] Dudley, N. (Ed.). (2008). Guidelines for Applying Protected Area Management Categories. IUCN, Gland.

[10] Day, J., Dudley, N., Hockings, M., Holmes, G., Laffoley, D. D. A., Stalton, S., \& Wells, S. M. (2012). Guidelines for applying the IUCN protected area management categories to marine protected areas. IUCN.

[11] Da Silva, A. P. (2019). Brazilian large-scale marine protected areas: Other "paper parks"? Ocean and Coastal Management, 169: $169-112$.

[12] CBD. (2010). The strategic plan for biodiversity 2011-2020 and the Aichi biodiversity targets. Nagoya, Japan: CBD.

[13] Dang, V. H., 2014. Marine Protected Areas Network in the South China Sea: Charting a Course for Future Cooperation. Martinus Nijhoff, Leiden.

[14] Guerreiro, J., Chircop, A., Dzidzornu, D., Grilo, C., Ribeiro, R., Van der Elst, R., Viras, A., 2001. The role of international environmental instruments in enhancing transboundary marine protected areas: an approach in East Africa. Mar. Pol. 35, 95104. https://doi.org/10.1016/j.marpol.2010.06.013. Instituto Brasileiro de Geografia e Estatistica (IBGE), 2011. Atlas geografico das zonas costeiras e oceanicas do Brasil. IBGE, Rio de Janeiro.

[15] Rife, A. N., Erisman, B., Sanchez, A., Aburto-Oropeza, O., 2013. When good intentions are not enough...Insights on networks of "paper park" marine protected areas. Conserv. Lett. 6, 200-212. https://doi.org/10.1111/j.1755-263X.2012.00303.x. 
[16] Grorud-Colvert, K., Claudet, J., Tissot, B. N., Caselle, J. E., Carr, M. H., Day, J. C., Friedlander, A. M., Lester, S. E., de Loma, T. L., Malone, D., Walsh, W. J. (2014). Marine protected area networks: assessing whether the whole is greater than the sum of its parts. PLoS One 9 e102298. https://doi.org/10.1371/journal.pone.0102298.

[17] Abowei, J. F. N. \& Ogamba, E. N. (2013). Effects of water pollution in Koluama Area, Niger Delta area, Nigeria fish species composition, histology, shrimp fishery and fishing gear type. Research Journal of Applied Sciences, Engineering and Technology, 6 (3), 373-381.

[18] Gomez, C., \& Green, D. R. (2013). The impact of oil and gas drilling accidents on EU fisheries. EU-Directorate General for Internal Policies.

[19] Nwilo, P. C., \& Badejo, O. T. (2005, May). Oil spill problems and management in the Niger Delta. In International oil spill conference (Vol. 2005, No. 1: 567-570). American Petroleum Institute.

[20] Adeyemo, O. K., Ubiogoro, O. E., and Adedeji, O. B. (2010). Oil exploitation, fisheries resources and sustainable livelihood in the Niger Delta, Nigeria. Nature \& Fauna, 24 (1): 56-61.

[21] Manby, B. (1999). The price of oil: Corporate responsibility and human rights violations in Nigeria's oil producing communities. (Vol. 2. 156). Human Rights Watch.

[22] Akpofure, E. A., Efere, M. L. \& Ayawei, P. (2000). The Adverse Effects of Crude Oil Spills in the Niger Delta. Urhobo Historical Society, 1, 21-33.

[23] Aworawo, D. (2000). The impact of environmental degradation of the rural economy of the Niger Delta. In Osuntokun, A. Environmental problems of the Niger Delta. Lagos, Friedrich Ebert Foundation. 